\title{
Candy, Snack Food, and Soda in the Checkout Lines of Stores Selling Products for Children in New York City
}

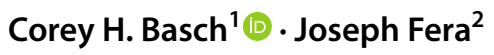

Accepted: 2 March 2021 / Published online: 12 March 2021

(c) The Author(s), under exclusive licence to Springer Science+Business Media, LLC, part of Springer Nature 2021

\begin{abstract}
While genetic and hormonal factors likely play a role in the development of obesity, lifestyle issues such as diet and physical activity are main contributors. Lifestyle issues are largely influenced by environmental factors, which pertain not only to access and availability, but exposure to opportunities for unplanned food and beverage purchases. The purpose of this study was to describe the extent to which candy, snack foods, and sugary beverages are available in checkout lines in a convenience sample retail chain stores in NYC that sell products for children. Non-probability, convenience sampling was used to select a total of 22 stores to visit in person. All stores were visited and the checkout lines were observed, capturing both the checkout style (single lane versus multiple lane; corralled or non-corralled), and the products (if any) being sold. Of the 22 stores surveyed, 17 (77.27\%) sold at least one convenience food (candy and snacks), and/or sugary beverages. Among the stores that sell convenience food, nearly all $(82.35 \%)$ sell candy, $100 \%$ of those with no corral-style line and $76.92 \%$ of those using a corral-style line. The findings from this study concur with prior research indicating that non-nutritious food items and sugary beverages have a presence at checkout areas of retail stores, thus driving the possibility for impulse buys. Exposure to messaging and ques are potentially influential on public health, and should be a point of reflection in terms of the kinds of policies that can support or hinder public health.
\end{abstract}

Keywords Candy $\cdot$ Soda $\cdot$ Snack food $\cdot$ Retail $\cdot$ Checkout $\cdot$ Children $\cdot$ New York City

\section{Introduction}

In the United States, (US) childhood obesity is a severe problem, with the US Centers for Disease Control and Prevention (CDC) reporting the prevalence of obesity in children and adolescents to be $18.5 \%$ [1]. Obesity is affecting over 13.7 million children and adolescents in the US [1]. In New York State, the rates of obesity have tripled in the prior three decades in children and adolescents [2]. At the present time, it is estimated that one-third of the children in New York State are obese or overweight [1]. In New York City (NYC) specifically, obesity is rampant. The CDC reports that $39 \%$ of NYC Public School children in kindergarten

Corey H. Basch

baschc@wpunj.edu

1 Department of Public Health, William Paterson University, University Hall 366, Wayne, NJ 07470, USA

2 Department of Mathematics, Lehman College, The City University of New York, New York 10468, USA through eighth grade are overweight or obese, which is higher than the national average [3].

The consequences of childhood obesity are dire. Eminent physical health problems associated with childhood obesity include increased risk factors for cardiovascular disease [4, 5], musculoskeletal issues [6,7], sleep apnea [8], fatty liver disease [9], asthma [10], increased risk for type 2 diabetes $[11,12]$, and others. In addition, psychosocial issues related to childhood obesity impact mental health. These issues include depression and anxiety [13,14], as well as the repercussions from potential stigmatization and bullying [15-17].

While genetic and hormonal factors likely play a role in the development of obesity, lifestyle issues such as diet and physical activity are main contributors [18]. Lifestyle issues are largely influenced by environmental factors, which pertain not only to access and availability, but exposure to opportunities for unplanned purchases [19]. Research suggests that there are many factors that influence all decisions one makes, including contextual factors such as impulse marketing, which prompt decisions in haste [20]. Product placement is a masterful and effective way to influence 
purchases at the point of sale [21]. Strategic and deliberate, this results in increased sales of snack foods and sugary beverages [20]. It is suggested that consumers spend over five thousand dollars annually on impulse purchases [22]. The extent to which snack foods [23-25] and sugary beverages $[26,27]$ have influenced the childhood obesity epidemic in the United States is well established.

In large metropolitan areas where obesity is problematic for children, it is important to consider the abundance of opportunities for exposure to such foods and beverages due to the sheer volume of retail outlets. It is documented that outlets whose purpose is to sell food and beverages often promote those with low nutritional quality [20, 28-30]. However, there is a paucity of research that examines point of sale placement in retail outlets whose focus is to sell products other than food and beverages. Therefore, the purpose of this study was to describe the extent to which candy, snack foods, and sugary beverages are available in checkout lines in a convenience sample retail chain stores in NYC that sell products for children.

\section{Methods}

The methods for this study mirrored those from a pilot study conducted in a different geographical region [31]. Searches were conducted on Google to determine the presence of chain stores located within NYC. For the purpose of this study, chain stores were considered those with multiple stores in the area that sold the same merchandise, which was confirmed by visiting all store websites under the information and locations tabs. Additionally, only stores which sold at least one type of merchandise for children (clothing, shoes, crafts, books etc.) were included. Non-probability, convenience sampling was used to select a total of 22 stores to visit in person. All stores were visited in October 2020 and the checkout lines were observed, capturing both the checkout style (single lane versus multiple lane; corralled or non-corralled), and the products (if any) being sold. Coding involved using a pre-established coding sheet from the pilot study [31]. Coding included line type, type of children's product sold, presence of convenience food, specific types of convenience foods and beverages, and location of these products in relation to the line and register. Per policy, the Institutional Review Board at William Paterson University does not review non-human subjects' studies.

\section{Results}

The presence of convenience food (candy and snacks), and sugary beverages was observed and recorded at 22 different chain stores in NYC. The type of food present, line style (corral or no corral), and food proximity (throughout the line or in a singular spot) was also recorded. Descriptive statistics were tabulated and comparisons based on relative proportions were made. No statistical tests were run due to the relatively low sample sizes.

Table 1 indicates the number of chains of each store present in NYC along with the type of products sold. Of the stores included, 12 (54.55\%) sell toys, crafts, books, and/or school supplies while 14 (63.64\%) carry clothing and shoes. Only $2(0.09 \%)$ sell accessories.

Of the 22 stores surveyed, 17 ( $77.27 \%)$ sold at least one convenience food (candy and snacks), and/or sugary beverages. Among these 17 stores, 13 (76.47\%) implement corralstyle lines and 4 (23.53\%) do not. Additionally, 8 out of these 17 stores $(47.06 \%)$ have the convenience food they sell available throughout the line, while 9 of the 17 (52.94\%) only have the food items available in a singular spot at the register.

The categories of convenience food considered in this study are included in Table 2 along with a count (and relative percent among those stores selling convenience food) of the stores selling this category of food. In addition, Table 2 shows

Table 1 Chain stores included in this study along with the number of chains present in NYC and the types of products sold

\begin{tabular}{|c|c|c|c|c|}
\hline \multirow{2}{*}{$\begin{array}{l}\text { Chain } \\
\text { store } \\
\text { number }\end{array}$} & \multirow{2}{*}{$\begin{array}{l}\text { Number of } \\
\text { stores in } \\
\text { NYC }\end{array}$} & \multicolumn{3}{|l|}{ Products sold } \\
\hline & & $\begin{array}{l}\text { Toys, crafts, } \\
\text { books, school } \\
\text { supplies }\end{array}$ & Accessories & $\begin{array}{l}\text { Cloth- } \\
\text { ing and } \\
\text { shoes }\end{array}$ \\
\hline 1 & 7 & $X$ & & \\
\hline 2 & 10 & $X$ & & \\
\hline 3 & 20 & $X$ & & $X$ \\
\hline 4 & 13 & $X$ & & $X$ \\
\hline 5 & 8 & $X$ & & \\
\hline 6 & 9 & & & $X$ \\
\hline 7 & 20 & $X$ & & \\
\hline 8 & 14 & & & $X$ \\
\hline 9 & 19 & & & $X$ \\
\hline 10 & 15 & & & $X$ \\
\hline 11 & 20 & & & $X$ \\
\hline 12 & 21 & $X$ & & \\
\hline 13 & 4 & & & $X$ \\
\hline 14 & 11 & & & $X$ \\
\hline 15 & 11 & $\mathrm{X}$ & $X$ & $X$ \\
\hline 16 & 20 & & $X$ & $\mathrm{X}$ \\
\hline 17 & 9 & $X$ & & $X$ \\
\hline 18 & 12 & $X$ & & \\
\hline 19 & 13 & $X$ & & \\
\hline 20 & 6 & & & $X$ \\
\hline 21 & 4 & & & $X$ \\
\hline 22 & 21 & X & & \\
\hline
\end{tabular}


Table 2 Food type present among stores with convenience food including a comparison by line type and proximity

\begin{tabular}{|c|c|c|c|c|c|c|}
\hline \multirow[t]{2}{*}{ Food type } & \multicolumn{2}{|c|}{ All (N=17) } & \multicolumn{2}{|l|}{ Line type } & \multicolumn{2}{|l|}{ Proximity } \\
\hline & Count $\mathrm{N}$ & Percent $\%$ of 17 & $\begin{array}{l}\text { Corral }(\mathrm{N}=13) \mathrm{N} \\
(\% \text { of } 13)\end{array}$ & $\begin{array}{l}\text { No corral }(\mathrm{N}=4) \\
\mathrm{N}(\% \text { of } 4)\end{array}$ & $\begin{array}{l}\text { Throughout }(\mathrm{N}=8) \\
\mathrm{N}(\% \text { of } 8)\end{array}$ & $\begin{array}{l}\text { Singular } \\
(\mathrm{N}=9) \mathrm{N}(\% \\
\text { of } 9)\end{array}$ \\
\hline Crackers & 2 & 11.76 & $2(15.38 \%)$ & $0(0 \%)$ & $1(12.5 \%)$ & $1(11.11 \%)$ \\
\hline Candy & 14 & 82.35 & $10(76.92 \%)$ & $4(100 \%)$ & $7(87.5 \%)$ & $7(77.78 \%)$ \\
\hline Soda, sugary beverages & 7 & 41.18 & $6(46.15 \%)$ & $1(25 \%)$ & $6(75 \%)$ & $1(11.11 \%)$ \\
\hline $\begin{array}{l}\text { Candied popcorn, chocolate } \\
\text { pretzels, etc }\end{array}$ & 4 & 23.53 & $4(30.77 \%)$ & $0(0 \%)$ & $3(37.5 \%)$ & $1(11.11 \%)$ \\
\hline Chips & 4 & 23.53 & $4(30.77 \%)$ & $0(0 \%)$ & $3(37.5 \%)$ & $1(11.11 \%)$ \\
\hline Preserved meats & 1 & 5.88 & $1(7.69 \%)$ & $0(0 \%)$ & $1(12.5 \%)$ & $0(0 \%)$ \\
\hline Cookies & 5 & 29.41 & $5(38.46 \%)$ & $0(0 \%)$ & $3(37.5 \%)$ & $2(22.22 \%)$ \\
\hline
\end{tabular}

Percentages included are relative to the total count in the given category

a breakdown of convenience food sold based on store line type used (corral or no corral) and the proximity of the food available in the line (throughout or singular spot).

Among the stores that sell convenience food, nearly all $(82.35 \%)$ sell candy, $100 \%$ of those with no corral-style line and $76.92 \%$ of those using a corral-style line. Only one of the 17 (5.88\%) stores surveyed sold preserved meats. This single store uses a corral-style line and has food present throughout the line. While $30.77 \%$ of the stores using corral lines sell candied popcorn, chocolate pretzels, etc. and chips, none of the stores using non-corral line styles sell these convenience food items. With regards to soda and sugary beverages, $75 \%$ of stores with convenience food located throughout their line carry these items while only $11.11 \%$ of stores providing food in a singular spot sell this category of food. Interestingly, the only types of convenience food items present in stores that do not use corral-style lines were candy and soda/sugary beverages. None of the other convenience foods were available in these stores.

Among the 22 stores, there are 10 with 10 or fewer (small) chain locations and 12 with more than 10 (large) chain locations throughout NYC. Among the 10 small stores, there are $2(20 \%)$ that do not carry convenience food items. A total of $3(25 \%)$ of the larger stores do not carry convenience food. In total, $75 \%$ of the smaller stores carry candy and $25 \%$ sell soda/ sugary beverages. In comparison, $66.67 \%$ of larger stores have candy available and $41.67 \%$ have soda/sugary beverages for sale. This means that a majority of all stores (small or large), a majority of small stores, and a majority of large stores sell candy.

\section{Discussion}

The findings from this study concur with prior research indicating that non-nutritious food items and sugary beverages have a presence at checkout areas of retail stores, thus driving the possibility for impulse buys [31, 32]. Further, line style may play a role in purchasing behavior considering the popularity of corral style lines, whereby customers are exposed to multiple non-nutritious food items while they wait to reach the register. While many studies related to checkout line foods take place in grocery or convenience stores, this study focused exclusively on stores that sell products for children, as childhood obesity is eminent public health issue in NYC. In addition, children are susceptible to the strategic marketing tactics to drive their caregivers to make impulse purchases of convenience foods of low nutritional quality and sugar sweetened beverages are problematic from a public health perspective [33-35].

These data are an example of how marketing to children and families may make it more difficult for making informed decisions about dietary intake. There are limited examples whereby such research has informed policy. Recently, the City Council in Berkley California banned unhealthy food from checkouts at large retailers [36]. This policy "forbids food items with $5 \mathrm{~g}$ of added sugars and $200 \mathrm{mg}$ of sodium, chewing gum and mints with added sugars, and beverages with added sugars or artificial sweeteners. [36]." Thus, serving as a model that other municipalities may consider. 
This study is not without limitations. By virtue of the cross-sectional design and the sampling method, the results are deemed non-generalizable. While one cannot guarantee that one store in the chain reflects the set-up of all stores in that chain, there is a strong case that these stores are intentionally set up in a homogenized way. In fact, that is a defining feature of stores of this nature [37]. Further, there may be limitations or alterations to item availability or store set up due to the on-going COVID-19 pandemic. Nevertheless, this study ads to the existing work that examines the presence of these products specifically at non-grocery-based retail venues.

Exposure to messaging and ques are potentially influential on public health, and should be a point of reflection in terms of the kinds of policies that can support or hinder public health. The findings from this study highlight the dilemma between the rights of businesses to sell products they choose with accompanying marketing tactics and the choice of governments to regulate such practices. Municipalities should reflect on practices that foster corporate profit at the expense of children's health.

Author Contributions CB conceptualized the study and collected the data. JF analyzed the data. Both contributed to the writing and revision of the manuscript.

\section{Declarations}

Conflict of interest None of the authors report a conflict of interest.

Ethical Approval As per the protocol at William Paterson University, the Institutional Review Board does not review studies that do not involve human subjects.

\section{References}

1. United States Centers for Disease Control and Prevention (CDC). (2021). Childhood Obesity Facts. Retrieved from https://www. cdc.gov/obesity/data/childhood.html

2. New York State Department of Health. (2020). Obesity prevention. Retrieved from https://www.health.ny.gov/prevention/obesi ty/\#: :text=Obesity\%20Prevalence,over\%20the\%20past $\% 20$ thr ee\%20decades

3. United States Centers for Disease Control and Prevention (CDC). (2013). Community profile: New York City, New York. Retrieved from https://www.cdc.gov/nccdphp/dch/programs/communitie sputtingpreventiontowork/communities/profiles/both-ny_newyo rkcity.html

4. Leopold, S., \& Zachariah, J. P. (2020). Pediatric obesity, hypertension, lipids. Current Treatment Options in Pediatrics, 6(2), 62-77. https://doi.org/10.1007/s40746-020-00188-2

5. Celik, O., Ozturk, D., Akin, F., Satilmis, S., Yalcin, A. A., Erturk, M., Ayca, B., Akturk, F., Birand, A., Pusuroglu, H., \& Kaya, M. G. (2015). Evaluation of lipoprotein-associated phosholipase A2 and plaque burden/composition in young adults.
Coronary Artery Disease, 26(3), 266-271. https://doi.org/10. 1097/MCA.0000000000000224

6. Krul, M., van der Wouden, J. C., Schellevis, F. G., van Suijlekom-Smit, L. W., \& Koes, B. W. (2009). Musculoskeletal problems in overweight and obese children. Annals of Family Medicine, 7(4), 352-356. https://doi.org/10.1370/afm.1005

7. Paulis, W. D., Silva, S., Koes, B. W., \& van Middelkoop, M. (2014). Overweight and obesity are associated with musculoskeletal complaints as early as childhood: A systematic review. Obesity Reviews, 15(1), 52-67. https://doi.org/10.1111/obr. 12067

8. Andersen, I. G., Holm, J. C., \& Homøe, P. (2016). Obstructive sleep apnea in obese children and adolescents, treatment methods and outcome of treatment-A systematic review. International Journal of Pediatric Otorhinolaryngology, 87, 190-197. https:// doi.org/10.1016/j.ijporl.2016.06.017

9. Africa, J. A., Newton, K. P., \& Schwimmer, J. B. (2016). Lifestyle interventions including nutrition, exercise, and supplements for nonalcoholic fatty liver disease in children. Digestive Diseases and Sciences, 61(5), 1375-1386.

10. Peters, U., Dixon, A. E., \& Forno, E. (2018). Obesity and asthma. The Journal of Allergy and Clinical Immunology, 141(4), 11691179. https://doi.org/10.1016/j.jaci.2018.02.004

11. Pulgaron, E. R., \& Delamater, A. M. (2014). Obesity and type 2 diabetes in children: Epidemiology and treatment. Current Diabetes Reports, 14(8), 508. https://doi.org/10.1007/ s11892-014-0508-y

12. Hockett, C. W., Praveen, P. A., Ong, T. C., Amutha, A., Isom, S. P., Jensen, E. T., D’Agostino, R. B., Jr., Hamman, R. F., MayerDavis, E. J., Lawrence, J. M., Pihoker, C., Kahn, M. G., Mohan, V., Tandon, N., \& Dabelea, D. (2021). Clinical profile at diagnosis with youth-onset type 1 and type 2 diabetes in two pediatric diabetes registries: SEARCH (United States) and YDR (India). Pediatric Diabetes, 22(1), 22-30. https://doi.org/10.1111/pedi. 12981

13 Lindberg, L., Hagman, E., Danielsson, P., Marcus, C., \& Persson, M. (2020). Anxiety and depression in children and adolescents with obesity: A nationwide study in Sweden. BMC Medicine, 18, 30. https://doi.org/10.1186/s12916-020-1498-Z

14. Quek, Y. H., Tam, W. W. S., Zhang, M. W. B., \& Ho, R. C. M. (2017). Exploring the association between childhood and adolescent obesity and depression: A meta-analysis. Obesity Reviews, 18(7), 742-754.

15. Suh, Y., Puhl, R., Liu, S., \& Fleming, M. F. (2014). Parental support for policy actions to reduce weight stigma toward youth in schools and children's television programs: Trends from 2011 to 2013. Childhood Obesity, 10(6), 533-541. https://doi.org/10. 1089/chi.2014.0050

16. Puhl, R. M., Luedicke, J., \& Depierre, J. A. (2013). Parental concerns about weight-based victimization in youth. Childhood Obesity, 9(6), 540-548. https://doi.org/10.1089/chi.2013.0064

17. Beck, A. R. (2016). Psychosocial aspects of obesity. NASN School Nurse, 31(1), 23-27. https://doi.org/10.1177/1942602X15619756

18. Mayo Clinic. (n.d.). Childhood obesity. Retrieved from https:// www.mayoclinic.org/diseases-conditions/childhood-obesity/ symptoms-causes/syc-20354827\#: :text=Regularly\%20eating\% 20 high $\% 2$ Dcalorie $\% 20$ foods,in $\% 20$ obesity $\% 20$ in $\% 20$ some $\%$ 20people

19. Almay, J.,\& Wootanm, M. G. (2015). Center for Science in the Public Interest. Temptation at checkout. Retrieved from https:// cspinet.org/temptation-checkout

20. Cohen, D. A., \& Babey, S. H. (2012). Candy at the register-A risk factor of obesity and chronic disease. New England Journal of Medicine, 367, 1381-1383. 
21. Blasinsky, C. (2017). Managing the candy aisle. National Association of Convenience Stores Magazine. Retrieved from https:// www.nacsmagazine.com/issues/may-2017/managing-candy-aisle

22. O'Brien, S. (2018). Consumers cough up $\$ 5400$ a year on impulse purchases. Retrieved from https://www.cnbc.com/2018/02/23/ consumers-cough-up-5400-a-year-on-impulse-purchases.html

23 Gordon-Larsen, P. (2014). Food availability/convenience and obesity. Advances in Nutrition, 5(6), 809-817. https://doi.org/10. 3945/an.114.007070

24. Odoms-Young, A., Singleton, C. R., Springfield, S., McNabb, L., \& Thompson, T. (2016). Retail environments as a venue for obesity prevention. Current Obesity Reports, 5(2), 184-191. https:// doi.org/10.1007/s13679-016-0219-6

25 Caspi, C. E., Sorensen, G., Subramanian, S. V., \& Kawachi, I. (2012). The local food environment and diet: A systematic review. Health \& Place, 18(5), 1172-1187. https://doi.org/10.1016/j.healt hplace.2012.05.006

26 BucherDellaTorre, S., Keller, A., Laure Depeyre, J., \& Kruseman, M. (2016). Sugar-sweetened beverages and obesity risk in children and adolescents: A systematic analysis on how methodological quality may influence conclusions. Journal of the Academy of Nutrition and Dietetics, 116(4), 638-659. https://doi.org/10. 1016/j.jand.2015.05.020

27 Malik, V. S., Pan, A., Willett, W. C., \& Hu, F. B. (2013). Sugarsweetened beverages and weight gain in children and adults: A systematic review and meta-analysis. The American Journal of Clinical Nutrition, 98(4), 1084-1102. https://doi.org/10.3945/ ajcn.113.058362

28. Glanz, K., Bader, M. D., \& Iyer, S. (2012). Retail grocery store marketing strategies and obesity: An integrative review. American Journal of Preventive Medicine, 42(5), 503-512. https://doi.org/ 10.1016/j.amepre.2012.01.013

29. Ethan, D., Samuel, L., \& Basch, C. H. (2013). An analysis of Bronx-based online grocery store circulars for nutritional content of food and beverage products. Journal of Community Health, 38(3), 521-528. https://doi.org/10.1007/s10900-012-9643-z
30. Samuel, L., Basch, C. H., Ethan, D., Hammond, R., \& Chiazzese, K. (2014). An analysis of sodium, total fat and saturated fat contents of packaged food products advertised in Bronx-based supermarket circulars. Journal of Community Health, 39(4), 775-782. https://doi.org/10.1007/s10900-014-9829-7

31. Basch, C. H., Kernan, W. D., \& Menafro, A. (2016). Presence of candy and snack food at checkout in chain stores: Results of a pilot study. Journal of Community Health, 41, 1090-1093. https://doi. org/10.1007/s10900-016-0193-7

32. Center for Science in the Public Interest. (2014). Sugar overload: Retail checkout promotes obesity. Retrieved from https://cspinet. $\mathrm{org} / \mathrm{sites} / \mathrm{default} /$ files/attachment/sugaroverload.pdf

33. Haigh, C., \& Durham, S. (2012). Checkouts checked out: How supermarkets and high street stores promote junk food to children and their parents. Children's Food Campaign.

34. Harris, J. L., Pomeranz, J. L., Lobstein, T., \& Brownell, K. D. (2009). A crisis in the marketplace: How food marketing contributes to childhood obesity and what can be done. Annual Review of Public Health, 30, 211-225. https://doi.org/10.1146/annurev. publhealth.031308.100304

35. Collier, R. (2015). Call to reduce junk food at checkouts. Canadian Medical Association Journal, 187(1), E14. https://doi.org/ 10.1503/cmaj.109-4940

36. Teller, E. (2020). Berkeley will be first in the nation to ban candy, soda at checkout aisles. Retrieved from https://www.berkeleysi de.com/2020/09/23/berkeley-will-be-first-in-the-nation-to-bancandy-soda-at-checkout-aisles

37. Chron. (2021). Difference between and department store and a chain store. Retrieved from https://smallbusiness.chron.com/diffe rence-between-department-store-chain-store-24127.html

Publisher's Note Springer Nature remains neutral with regard to jurisdictional claims in published maps and institutional affiliations. 